\title{
PENGARUH KUALITAS PELAYANAN DAN LINGKUNGAN FISIK TERHADAP KEPUASAN PASIEN PADA YAYASAN PEDULI KEMANUSIAAN (YPK) BALI DI DENPASAR
}

\author{
Ni Kadek Ayu Trisna Dewi ${ }^{1}$ \\ Ida Ayu Arini ${ }^{2}$ \\ ${ }^{1,2}$ Fakultas Ekonomi Universitas Ngurah Rai, Bali, Indonesia \\ 1e-mail : trisnadewi2108@gmail.com
}

\begin{abstract}
ABSTRAK
Penelitian ini bertujuan untuk mengetahui kualitas pelayanan dan lingkungan fisik berpengaruh positif dan signifikan secara parsial maupun simultan terhadap kepuasan pasien pada YPK Bali. Metode pengumpulan data yang digunakan adalah observasi, wawancara dan studi dokumentasi. Jumlah sampel yang digunakan adalah sebanyak 52 orang responden. Responden dalam penelitian ini adalah pendamping dari pasien yang menerima pelayanan pada YPK Bali. Data dianalisis dengan menggunakan uji asumsi klasik, analisis regresi linier berganda, analisis determinasi, analisis statistik uji t (t-test) dan analisis statistik uji F (F-test). Hasil penelitian menunjukkan bahwa kualitas pelayanan dan lingkungan fisik berpengaruh positif dan signifikan secara parsial maupun simultan terhadap kepuasan pasien pada YPK Bali.
\end{abstract}

Kata kunci : Kualitas Pelayanan, Lingkungan Fisik dan Kepuasan Konsumen

\section{ABSTRACT}

This study aims to find out the service quality and physical environment have a positive and significant effect partially or simultaneously on patient satisfaction at YPK Bali. Data collection methods used were observation, interviews and documentation studies. The number of samples used were 52 respondents. Respondents in this study were assistants from patients who received service at YPK Bali. Data were analyzed using classic assumption test, multiple linear regression analysis, determination analysis, $t$-test statistical analysis ( $t$-test) and $F$-test ( $F$-test) statistical analysis. The results showed that service quality and physical environment had a positive and significant effect partially or simultaneously on patient satisfaction at YPK Bali.

Keywords: Service Quality, Physical Environtment and Customer Satisfaction. 


\section{PENDAHULUAN}

Dewasa ini kesehatan
merupakan suatu kebutuhan yang mendasar bagi masyarakat. Oleh karena itulah masyarakat merasa perlu menjaga kesehatan dan memperoleh pelayanan kesehatan yang sebaik mungkin. Berdasarkan data dari Forum Indonesia Development, 2018 menunjukkan bahwa jumlah penduduk penyandang disabilitas di Indonesia saat ini adalah sebesar 11.580 .117 orang diantaranya 3.010 .830 orang atau sekitar 25,99\% merupakan penyandang disabilitas fisik. Yayasan Peduli Kemanusiaan Bali atau YPK Bali merupakan salah satu yayasan sosial yang didirikan sejak tahun 2001 di Denpasar sebagai bentuk respon terhadap keprihatinan kepada para penyandang disabilitas fisik di Bali yang sangat membutuhkan dukungan moral serta terapi fisik yang berkelanjutan. Dalam upaya untuk memahami kebutuhan dan keinginan pasien maka YPK Bali sebagai penyedia jasa pelayanan kesehatan selalu berupaya untuk meningkatkan kualitas layanannya yang mampu memberikan kepuasan pada pasien di YPK Bali.

Kualitas pelayanan adalah ukuran seberapa bagus tingkat layanan yang diberikan sesuai dengan harapan pelanggan (Fandy Tjiptono 2012:157). Kualitas pelayanan yang bagus akan mampu meningkatkan kepuasan bagi penerima layanan tersebut. Dalam hal ini pihak YPK Bali sudah berusaha memberikan pelayanan yang maksimal namun berdasarkan observasi yang dilakukan menunjukkan bahwa kebanyakan pasien mengatakan pelayanan yang mereka terima tidak sesuai dengan harapan mereka, seperti misalnya kurangnya kemampuan staf fisioterapi dalam membaca rekam medis pasien, pemberian informasi yang kurang jelas, lahan parkir yang kurang memadai, penampilan staf yang kurang rapi dan sopan, waktu terapi yang terlalu singkat, lahan parkir yang sempit serta petunjuk masing-masing ruangan kurang jelas.
Lingkungan fisik merupakan salah satu unsur pembentuk bauran jasa. Lingkungan fisik merupakan segala sesuatu yang secara fisik terdapat di sekitar konsumen selama pertemuan transakasi layanan jasa tersebut. Berdasarkan observasi awal diperoleh bahwa beberapa pasien mengeluhkan suasana lingkungan fisik pada unit rehabilitasi di YPK Bali kurang nyaman, seperti misalnya; ruangan terapi yang terlalu sempit, penempatan peralatan terapi yang kurang baik dan alas kaki yang kurang rapi sehingga mempersulit atau mengganggu akses pasien yang menggunakan kursi roda, tidak adanya papan nama ruangan, pencahayaan ruangan yang redup sehingga membuat pasien anak-anak kurang nyaman.

Kepuasan merupakan perasaan senang atau kecewa seseorang yang muncul setelah membandingkan antara persepsi terhadap kinerja atau hasil suatu produk atau jasa dan harapanharapan. Jadi, tingkat kepuasan merupakan fungsi dari perbedaan antara kinerja yang dirasakan dengan harapan (Yunus dan Budiyanto, 2014 :7). Sebelumnya pihak YPK Bali pernah melakukan survey kepuasan pasien pada unit Rehabilitasi, akan tetapi tidak ditinjau lebih mendalam. Sehingga diperlukan lagi pengukuran tingkat kepuasan pasien pada unit Rehabilitasi YPK Bali. Berkaitan dengan hal tersebut, dilihat faktor kualitas pelayanan dan lingkungan fisik menjadi hal yang sangat penting untuk diperhatikan, karena konsumen akan merasa puas apabila tingkat kualitas pelayanan yang diberikan dan kondisi lingkungan fisik yang disediakan oleh pihak penyedia layanan (dalam hal ini YPK Bali) sesuai atau bahkan melebihi dari apa yang diharapkan oleh konsumen.

Adanya perhatian dan ditemui 
permasalahan berkaitan dengan kualitas pelayanan dan lingkungan fisik dalam usaha meningkatkan kepuasan pasien pada YPK Bali, maka sangat layak dalam penelitian ini diteliti lebih jauh lagi pengaruh kualitas pelayanan dan lingkungan fisik secara parsial maupun simultan terhadap kepuasan pasien pada YPK Bali di Denpasar.

Penelitian ini bertujuan untuk mengetahui pengaruh kualitas pelayanan dan lingkungan fisik berpengaruh postif dan signifikan secara parsial maupun simultan terhadap kepuasan pasien pada YPK Bali.

\section{METODE PENELITIAN}

Desain penelitian ini termasuk dalam penelitian kuantitatif yaitu penelitian deskriptif, yaitu penelitian untuk mendiskripsikan dan menjawab persoalan-persoalan suatu fenomena atau peristiwa yang terjadi saat ini. Populasi dalam penelitian ini adalah pasien aktif pada YPK Bali tahun 2018 sebanyak 207 orang pasien. Penentuan sampel berdasarkan pendapat Suharsimi Arikunto, yaitu $25 \%$ dari jumlah populasi sehingga jumlah sampel 52 orang responden.
Sumber data yang digunakan adalah data primer dan data sekunder. Teknik pengumpulan data dalam penelitian ini dilakukan dengan observasi, wawancara, studi dokumentasi dan kuesioner. Setiap jawaban kuesioner mempunyai bobot atau skor nilai dengan skala Likert sebagai berikut : STS (sangat tidak setuju = skor 1 , TS (tidak setuju) $=$ skor 2 , KS (kurang setuju) $=$ skor $3, \mathrm{~S}$ (setuju) $=$ skor $4, \mathrm{SS}$ (sangat setuju) $=$ skor 5 . Untuk mengukur item/ instrumen pernyataan kuesioner menggunakan alat uji validitas dan uji reliabilitas. Teknik analisis data dalam peelitian ini menggunkan pendekatan kuantitatif yaitu analisis statistik inferensial, terdiri dari : uji asumsi klasik, analisis koefisien regresi linier berganda, analisis determinasi, analisis statistik uji $\mathrm{t}($ uji-t) dan analisis statistik uji $\mathrm{F}(F-$ test).

\section{HASIL DAN PEMBAHASAN Uji Asumsi Klasik}

Uji asumsi klasik digunakan untuk mengetahui kelayakan penggunaan model regresi. Hasil uji multikolinieritas dapat dilihat pada Tabel 1.

Tabel 1

Hasil Uji Multikolinearitas

\begin{tabular}{|l|c|c|}
\hline \multirow{2}{*}{ Variabel Bebas } & \multicolumn{2}{|c|}{ Collinearity Statistic } \\
\cline { 2 - 3 } & Tolerance & VIF \\
\hline Kualitas Pelayanan & 0.834 & 1.199 \\
\hline Lingkungan Fisik & 0.834 & 1.199 \\
\hline
\end{tabular} Sumber: Hasil Olah Data SPSS 20.0 for Windows, 2019

Berdasarkan Tabel 1 dapat diketahui bahwa nilai VIF dibawah 10 dan nilai Tolerance diatas 0.1 menjelaskan tidak terjadi multikolinearitas atau tidak terjadi korelasi diantara variable kualitas pelayanan dan lingkungan fisik

Hasil uji heteroskedastisitas dapat dilihat pada Tabel 2 . 
Tabel 2

Hasil Uji Heteroskedastisitas

\begin{tabular}{|c|c|c|}
\hline Model & $\mathrm{t}$ & Sig. \\
\hline Konstanta & 0.000 & 1.000 \\
\hline Kualitas Pelayanan (X1) & 0.000 & 1.000 \\
\hline Lingkungan Fisik (X2) & 0.000 & 1.000 \\
\hline
\end{tabular}

Dari Tabel 2 diketahui hasil uji Glejser adalah probabilitas signifikansi variable kualitas pelayanan dan lingkungan fisik adalah sebesar 1,000 > $\square=0,05$. Hasil ini menunjukkan bahwa
Koefisien regresi nilai absolut residual tidak signifikan, sehingga tidak terjadi heteroskedastisitas pada variabel kualitas pelayanan dan lingkungan fisik. Hasil Uji normalitas dapat dilihat pada Tabel 3.

Tabel 3

Hasil Uji Normalitas

\begin{tabular}{|l|c|}
\hline & $\begin{array}{c}\text { Unstandardized } \\
\text { Residual }\end{array}$ \\
\hline $\mathrm{N}$ & 52 \\
Kolmogorov-Smirnov Z & 0,586 \\
Asymp. Sig. (2-tailed) & 0,882 \\
\hline
\end{tabular}

Sumber: Hasil Olah Data SPSS 20.0 for Windows, 2019

Berdasarkan Tabel 3 dapat diketahui bahwa nilai Asymp. Sig. (2tailed) sebesar 0,882 lebih besar dari $\square$ $=0,05$. Hal ini menjelaskan bahwa model regresi sudah memenuhi asumsi normalitas atau data berdistribusi normal.

Berdasarkan hasil uji asumsi klasik maka diketahui pada persamaan regresi tidak terjadi gejala multikolinearitas, tidak terjadi gejala heteroskedastisitas dan distribusi data adalah normal sehingga model regresi bisa digunakan karena mendapatkan hasil prediksi yang baik atau bisa memberikan manfaat dengan benar.

\section{Analisis Regresi Linear Berganda}

Hasil analisis regresi linear berganda dapat dilihat pada Tabel 4

Tabel 4

Hasil Uji Regresi Linear Berganda

\begin{tabular}{|c|c|c|}
\hline \multirow{2}{*}{$\begin{array}{c}\text { Variabe } \\
1\end{array}$} & \multicolumn{2}{|c|}{ Unstandardize } \\
\cline { 2 - 3 } & & $\begin{array}{c}\text { Standar } \\
\text { Error }\end{array}$ \\
\hline Konstanta & $\mathrm{B}$ & 2,656 \\
\hline Kualitas Pelayanan $\left(\mathrm{X}_{1}\right)$ & 0,050 & 0,024 \\
\hline Lingkungan Fisik $\left(\mathrm{X}_{2}\right)$ & 0,180 & 0,060 \\
\hline Sumber: Hasil Olah Data SPSS 20.0 for Windows, 2019
\end{tabular}




\begin{abstract}
Berdasarkan Tabel 4 diperoleh persamaan regresi linear berganda adalah : $\mathrm{Y}=1,431+0,050$ $\mathrm{X}_{1}+0,180 \mathrm{X}_{2}$ memberikan informasi bahwa : $\mathrm{a}=1,431$ artinya apabila tidak ada perhatian terhadap kualitas pelayanan dan lingkungan fisik atau nilainya adalah konstan atau nol maka skor kepuasan pasien pada YPK Bali adalah sebesar rata-rata 1,431 . b1 $=$ 0,050 artinya apabila variabel lingkungan fisik dianggap konstan maka meningkatnya nilai kualitas pelayanan sebesar satu satuan akan diikuti oleh meningkatnya nilai kepuasan pasien pada YPK Bali sebesar rata-rata 0,050 . b2 $=0,180$ artinya apabila variabel kualitas pelayanan dianggap konstan maka
\end{abstract}

meningkatnya nilai lingkungan fisik sebesar satu satuan akan diikuti oleh meningkatnya nilai kepuasan pasien pada YPK Bali sebesar rata-rata $\quad 0,180$. Jadi berdasarkan analisis regresi linear berganda menunjukkan bahwa adanya pengaruh yang positif dan signifikan secara simultan antara kualitas pelayanan dan lingkungan fisik terhadap kepuasan pasien. Koefisien regresi yang bertanda positif menunjukkan adanya pengaruh yang searah dimana jika secara simultan kualitas pelayanan dan lingkungan fisik meningkat maka akan diikuti oleh meningkatnya kepuasan pasien pada YPK Bali.

\title{
Analisis Determinasi
}

Hasil analisis determinasi dapat dilihat pada Tabel 5.

Tabel 5

Hasil Analisis Determinasi

\begin{tabular}{|c|c|c|}
\hline Model & $\mathrm{R}$ & $\mathrm{R}$ Square \\
\hline 1 & 0,561 & 0,315 \\
\hline \multicolumn{3}{|c|}{ Sumber: Hasil Olah Data SPSS 20.0 for Windows, 2019}
\end{tabular}

Berdasarkan Tabel 5 diperoleh koefisien determinasi adalah sebesar $31,5 \%$ menunjukkan bahwa besarnya kontribusi/sumbangan kualitas pelayanan dan lingkungan fisik terhadap kepuasan pasien pada YPK Bali adalah sebesar $31,5 \%$. Sedangkan sisanya sebesar $68,5 \%$ dipengaruhi oleh faktor- faktor lain yang tidak dibahas dalam penelitian ini.

\section{Analisis Statistik Uji t (t-test)}

Hasil uji hipotesis menggunakan uji statistik $\mathrm{t}$ (t-test) dapt dilihat pada Tabel 6.

\section{Tabel 6}

Hasil Analisis Uji t-test

\begin{tabular}{|l|c|c|}
\hline \multicolumn{1}{|c|}{ Model } & t & Sign. T \\
\hline Konstanta & 0,539 & 0,593 \\
\hline Kualitas Pelayanan $\left(\mathrm{X}_{1}\right)$ & 2,126 & 0,390 \\
\hline Lingkungan Fisik $\left(\mathrm{X}_{2}\right)$ & 3,005 & 0,004 \\
\hline
\end{tabular}

Sumber: Hasil Olah Data SPSS 20.0 for Windows, 2019 
Berdasarkan Tabel 6, menunjukkan bahwa nilai t1-hitung diperoleh sebesar 2,126, sedangkan nilai t-tabel sebesar 1,677. Karena t1- hitung > t-tabel atau $2,126>1,677$ berarti kualitas pelayanan berpengaruh positif dan signifikan terhadap kepuasan pasien pada YPK Bali. Nilai t2-hitung diperoleh sebesar 3,005. Karena t2hitung > t-tabel atau 3,005>1,677, maka artinya lingkungan fisik berpengaruh positif dan signifikan terhadap kepuasan pasien pada YPK Bali. Sehingga dapat disimpulkan bahwa kualitas pelayanan dan lingkungan fisik berpengaruh positif dan signifikan secara parsial terhadap kepuasan pasien pada YPK Bali (hipotesis terbukti).

\section{Analisis Statistik Uji F (F-test)}

Hasil uji hipotesis menggunakan uji statistik F (F-test) dapat dilihat pada Tabel 7.

Tabel 7

Hasil Analisis Uji F-test

\begin{tabular}{|c|c|c|c|}
\hline Model & & $F$ & Sig. \\
\hline 1 & $\begin{array}{l}\text { Regression } \\
\text { Residual } \\
\text { Total }\end{array}$ & 11.247 & 0,000 \\
\hline
\end{tabular}

Hasil uji statistik $\mathrm{F}$ (F-test) diperoleh nilai F-hitung $=11,247$ Sedangkan nilai F-tabel sebesar 3,19. Oleh karena nilai F-hitung > F- tabel atau 11,247>3,19, berarti kualitas pelayanan dan lingkungan fisik berpengaruh positif dan signifikan secara simultan terhadap kepuasan pasien pada YPK Bali (hipotesis terbukti).

\section{PENUTUP \\ KESIMPULAN}

Koefisien regresi bertanda positif menunjukkan bahwa ada pengaruh yang searah, dimana jika secara simultan kualitas pelayanandan lingkungan fisik meningkat maka akan diikuti oleh meningkatnya kepuasan pasien pada YPK Bali.

Besarnya kontribusi/sumbangan kualitas pelayanan dan lingkungan fisik terhadap kepuasan pasien pada YPK Bali adalah sebesar $31,5 \%$. Sedangkan sisanya sebesar $68,5 \%$ dipengaruhi oleh faktor-faktor lain yang tidak dibahas dalam penelitian ini. Kualitas pelayanan dan lingkungan fisik berpengaruh positif dan signifikan secara parsial terhadap kepuasan pasien pada YPK Bali. Hal ini dibuktikan oleh besarnya nilai t1-hitung $=2,126$ dan t2-hitung $=3,005>$ nilai t-tabel $=1,677$.

Kualitas pelayanan dan lingkungan fisik berpengaruh positif dan signifikan secara simultan terhadap kepuasan pasien pada YPK Bali. Hal ini dibuktikan oleh besarnya nilai $\mathrm{F}$ hitung $=11,247>$ nilai F-tabel $=3,19$.

\section{SARAN-SARAN}

Kualitas pelayanan yang selama ini sudah baik hendaknya dipertahankan,dan bila perlu untuk kedepannya lebih ditingkatkan lagi.Dan perlu memaksimalkan beberapa hal yang dianggap kurang, seperti prosedur administrasi, jadwal dan waktu terapi pasien disesuaikan dengan kebutuhan pasien serta memperdalam kemampuan staf fisioterapi dalam membaca rekam medis pasien. 
Kepada pihak YPK Bali kiranya masih perlu untuk menambahkan beberapa hal yang berkaitan dengan lingkungan terapi seperti menyesuaikan pencahayaan di dalam ruang terapi, membuat peringatan tertulis mengenai kebisingan agar suasana tidak gaduh, membuat papan petunjuk pada setiap ruangan, serta memperbaiki penataan ruangan atau peralatan agar ruang gerak dan akses pasien lebih nyaman dan leluasa.

Kepada YPK Bali hendaknya menyediakan semacam kotak yang terdiri dari 2 kotak yaitu puas dan tidak puas dan juga menyediakan kartu untuk dimasukkan oleh pasien kedalam salah satu kotak yang mereka inginkan setiap selesai terapi. Dengan demikian akan dapat diketahui seberapa besar pasien merasa puas atau tidak puas terhadap pelayanan YPK Bali.

Diharapkan kepada peneliti selanjutnya hendaknya meneliti jumlah variabel yang lebih bervariasi lagi, sehingga dapat diketahui faktor- faktor lain untuk mengukur kepuasan pasien yang lebih maksimal pada YPK Bali.

\section{DAFTAR PUSTAKA}

Aji,W.K. (2011). Analisis Pengaruh Kualitas Pelayanan, Harga dan Fasilitas Terhadap Kepuasan Pasien (Studi Pada Pasien Klinik As Syifa di Kab.Bekasi). Skripsi, Fakultas Ekonomi Universitas Diponegoro Semarang.

Apriliani, B. (2018). Pengaruh

Lingkungan Fisik Terhadap Kepuasan Konsumen Pariwisata Pulau Pahawang Di Provinsi Lampung. $\quad$ Skripsi, Fakultas Ekonomi dan Bisnis Universitas Lampung.

Arikunto, S. (2013). Prosedur Penelitian Suatu Pendekatan Praktik. Jakarta: Rineka Cipta.

Ghozali, Imam. (2013). Aplikasi Analisis Multivariate Dengan Program SPSS. Edisi ke-7. Semarang :
Badan Penerbit Universitas Diponegoro.

Harfika, J. \& Abdullah, N. (2017). Pengaruh Kualitas Pelayanan Dan Fasilitas Terhadap Kepuasan Pasien Pada Rumah Sakit Umum Kabupaten Aceh Barat Daya. Jurnal Balance Vol. XIV No.1, Fakultas Ekonomi Universitas Muhammadiyah Aceh (Unmuha).

Haryanto,E. (2013). Kualitas

Layanan,Fasilitas Dan Harga Pengaruhnya Terhadap Kepuasan Pengguna Jasa Layanan Pada Kantor Samsat Manado. Jurnal ISSN 2303-1174, Fakultas Ekonomi dan Bisnis Universitas Sam Ratulangi Manado. http://ypkbali.org/.https://dentim.den pasarkota.go.id/index.p p/pro

Kotler, P., Kevin, K. \& Lane. (2009), Manajemen Pemasaran (13th ed.), Jakarta : PT Macanan Cemerlang.

Lupiyoadi, R. \& Hamdani, A. (2008), Manajemen Pemasaran Jasa Teori Dan Praktik, Jakarta : Selemba Empat.

Noor, Juliansyah. (2011).

Metodologi Penelitian. Jakarta: Kencana. Pudyartono \& Hasanah, A. (2015). Pengaruh Kualitas Pelayanan Dan Fasilitas Terhadap Kepuasan Pasien Rawat Jalan (Studi di UPT. Puskesmas Maduran Lamongan).Jurnal, Universitas Islam Darul 'Ulum Lamongan. 